\title{
Manejo intraoperatório em cirurgia laparoscópica ou robótica para minimizar a dispersão de aerossóis: Adaptações ao contexto da pandemia por COVID-19
}

\section{Laparoscopic or robotic intraoperative management to minimize aerosol dispersion: Adaptations to the context of the COVID-19 pandemic}

Andre luiz Giola Morrell1,2,30; Francisco Tustumi, ACBC-SP4; Alexander Charles Morrell-Junior 1,3; Allan Giola Morrell 1,3,5; Duarte Miguel Ferreira Rodrigues Ribeiro ${ }^{3,6}$; Paulo Roberto Corsi, TCBC-SP5; Alexander Charles Morrell, TCBC-SP1,2,3

R E S U M O

\begin{abstract}
A infecção pelo coronavírus determinante da doença COVID-19, também conhecida como SARS-COV2 foi classificada nos últimos meses como pandemia. Essa é potencialmente fatal, representando enorme problema de saúde mundial. A disseminação, após provável origem zoonótica na cidade de Wuhan, China, resultou em colapso do sistema de saúde de diversos países, alguns com enorme impacto social e número grande de mortes descritas na Itália e Espanha. Medidas extremas intra e extra-hospitalares têm sido implementadas a fim de conter a transmissão e disseminação da COVID-19. No âmbito cirúrgico, enorme quantidade de procedimentos considerados não essenciais ou eletivos foram prorrogados ou suspensos até resolução da pandemia. No entanto, cirurgias de urgência e oncológicas não permitem que o paciente espere. Nesta publicação, sugerimos e ensinamos adaptação a ser feita com materiais de uso corriqueiro em laparoscopias para evitar a contaminação ou a disseminação entre as equipes assistenciais e os pacientes.
\end{abstract}

Descritores: Laparoscopia. Aerossóis. Coronavirus. Pandemias. Período Intraoperatório.

\section{INTRODUÇÃO}

$\mathrm{O}$ novo coronavírus, primeiramente diagnosticado em Wuhan, China, no final do ano 2019, encontra-se disseminado por todo o globo'. Em março de 2020, a Organização Mundial da Saúde declarou o status de pandemia, elevando ao nível máximo de atenção os sistemas de saúde ao redor do mundo. As implicações em âmbitos de saúde, sociais, econômicos e políticos na tentativa de conter a alta disseminação mundial demonstram-se de forma dramática em todos os países afetados, vivenciandose corrida contra o tempo em busca de soluções.

Há hoje crescente exponencial de estudos a respeito da COVID-19 quanto à apresentação, transmissão, quadro clínico, diagnóstico e possíveis terapêuticas. Até o momento, os dados recém relatados configuram-se aquém dos mais sólidos níveis de evidência científica, porém a situação emergencial os torna valiosos. Em contrapartida, mundialmente, os hospitais têm tido crise de suprimentos, com escassez de leitos, número de profissionais para atendimento e assistência, dispositivos de ventilação mecânica e até equipamentos de proteção individual (EPI) essenciais no cuidado e controle da doença. Acredita-se que transmissão de pessoa para pessoa ocorra principalmente por contato direto ou por gotículas espalhadas pela tosse ou espirro de um indivíduo infectado, denominadas aerossóis².

A pandemia impactou enormemente nas rotinas das distintas áreas de saúde, incluindo a Cirurgia, criando a necessidade de enormes mudanças. Tem-se vivenciado o desconhecimento, a insegurança e a escassez de dados na literatura de forma substanciosa que possam orientar em como proceder frente às novidades.

\footnotetext{
1 - Instituto Morrell, Cirurgia do Aparelho Digestivo Minimamente Invasiva e Robótica - São Paulo - SP - Brasil. 2 - Sociedade Beneficente Israelita Brasileira Albert Einstein, Cirurgia Geral e do Aparelho Digestivo Minimamente Invasiva e Robótica - São Paulo - SP - Brasil. 3 - Rede D’Or São Luiz, Cirurgia do Aparelho Digestivo e Robótica - São Paulo - SP - Brasil. 4 - Universidade de São Paulo (FMUSP), Departamento de Cirurgia - São Paulo - SP - Brasil. 5 - Faculdade de Ciências Médicas da Santa Casa de São Paulo, Departamento de Cirurgia - São Paulo - SP - Brasil. 6 - Clínica Duarte Miguel Ribeiro, Cirurgia Geral e Ginecologica - São Paulo - SP - Brasil.
} 
Prontamente, entidades de maior representatividade, a exemplo; o Colégio Brasileiro de Cirurgiões (CBC), que mesmo cientes da baixa evidência científica atual, vieram nortear tais medidas de segurança geral para com os pacientes e equipes de saúde $e^{3,4}$.

Há evidência de que procedimentos laparoscópicos possam dispersar aerossol adjunto de partículas virais ${ }^{5,6}$. No entanto, ainda é questionável que o acesso aberto seja mais seguro ou não que procedimentos laparoscópicos no contexto da COVID-197. Dispositivos como o AirSeal iFS $®$ System ou Laparoshield ${ }^{\mathrm{TM}}$ Laparoscopic Smoke Filtration System, fabricados especificamente para filtragem laparoscópica de fumaça removendo partículas, células e vírus já foram desenvolvidos no mercado, embora ainda não existam estudos comprovando a eficácia especificamente para a COVID-19. No entanto, a disponibilidade destes dispositivos nos dias de pandemia e especificamente em países de menor potencial financeiro pode ser escassa.

Neste artigo, apresentamos uma manobra simples e reprodutível a ser realizada com materiais corriqueiros, passível de ser adotada no paciente cirúrgico durante a pandemia de COVID-19 em procedimento laparoscópico ou robótico. Em meio ao cenário da pandemia atual, buscamse ainda evidências mais concretas sobre efetiva diminuição de transmissão e resultados. Uma série de recomendações no ambiente cirúrgico podem ser realizadas a fim de possível menor transmissibilidade do vírus ${ }^{7,8}$. A adaptação descrita objetiva especificamente minimizar a dispersão de aerossóis no ambiente cirúrgico e tentar preservar a equipe de profissionais em atuação.

\section{RELATO TÉCNICO}

Preparo da sala cirúrgica: Como qualquer procedimento a ser realizado em paciente no contexto do COVID-19, o uso dos materiais de proteção é obrigatório9. Todos os profissionais de saúde envolvidos no procedimento devem usar gorro, óculos de proteção, máscara N95, face shield, além da paramentação esterilizada habitual para a equipe cirúrgica. Idealmente, devem-se utilizar salas com pressão negativa, sendo o procedimento de indução e garantia de via aérea definitiva realizado sem a presença da equipe cirúrgica completa, na presença de apenas um anestesista e um profissional de enfermagem auxiliandoo(a); com o menor número possível de profissionais no interior da sala. Uma vez, tendo o paciente a via aérea segura e o sistema ventilatório fechado conectado, a equipe cirúrgica deve entrar para posicionamento do paciente, montagem de mesa e demais necessidades para o ato cirúrgico.

Material: Antes do início da operação, deixar preparados dois cabos plásticos convencionais de aspiração ou irrigação, um dispositivo de selo d'água e um saco plástico transparente de ótica laparoscópica esterilizado. Solicite que o profissional auxiliar da sala cirúrgica prepare solução de ácido hipocloroso ( $\mathrm{HClO}$ ) a 2 ou 2,5\% (conhecida também como água sanitária), diluída em água numa proporção de $25 \mathrm{~mL}$ de ácido hipocloroso em $975 \mathrm{~mL}$ de água, totalizando solução de $1000 \mathrm{~mL}$. Tal solução foi recentemente reportada como fatal ao vírus ${ }^{10}$. Outra solução química também possível para uso é o dióxido de cloro estabilizado a 7\% com diluição de $5 \mathrm{~mL}$ do produto em $1000 \mathrm{~mL}$ de água ${ }^{11}$. Utilize uma dessas soluções para preencher o reservatório de selo d'água a fim de submergir o orifício final da cânula de plástico do selo d'água (Figura1). Por fim, deve-se fechar o reservatório com a devida tampa e conectar o primeiro cabo de aspiração ao selo d'água no orifício A conforme figura a seguir (Figura 2A).

Punções e pneumoperitônio: Para a realização do pneumoperitônio no procedimento minimamente invasivo, orienta-se a confecção do mesmo pela técnica com utilização da agulha de Veress. A utilização de pressão intraperitoneal no menor valor seguro possível para a realização da primeira punção e manutenção do campo operatório é desejável, estimando-se oscilação entre 10-15 mmHg. 


\section{MorReLl}
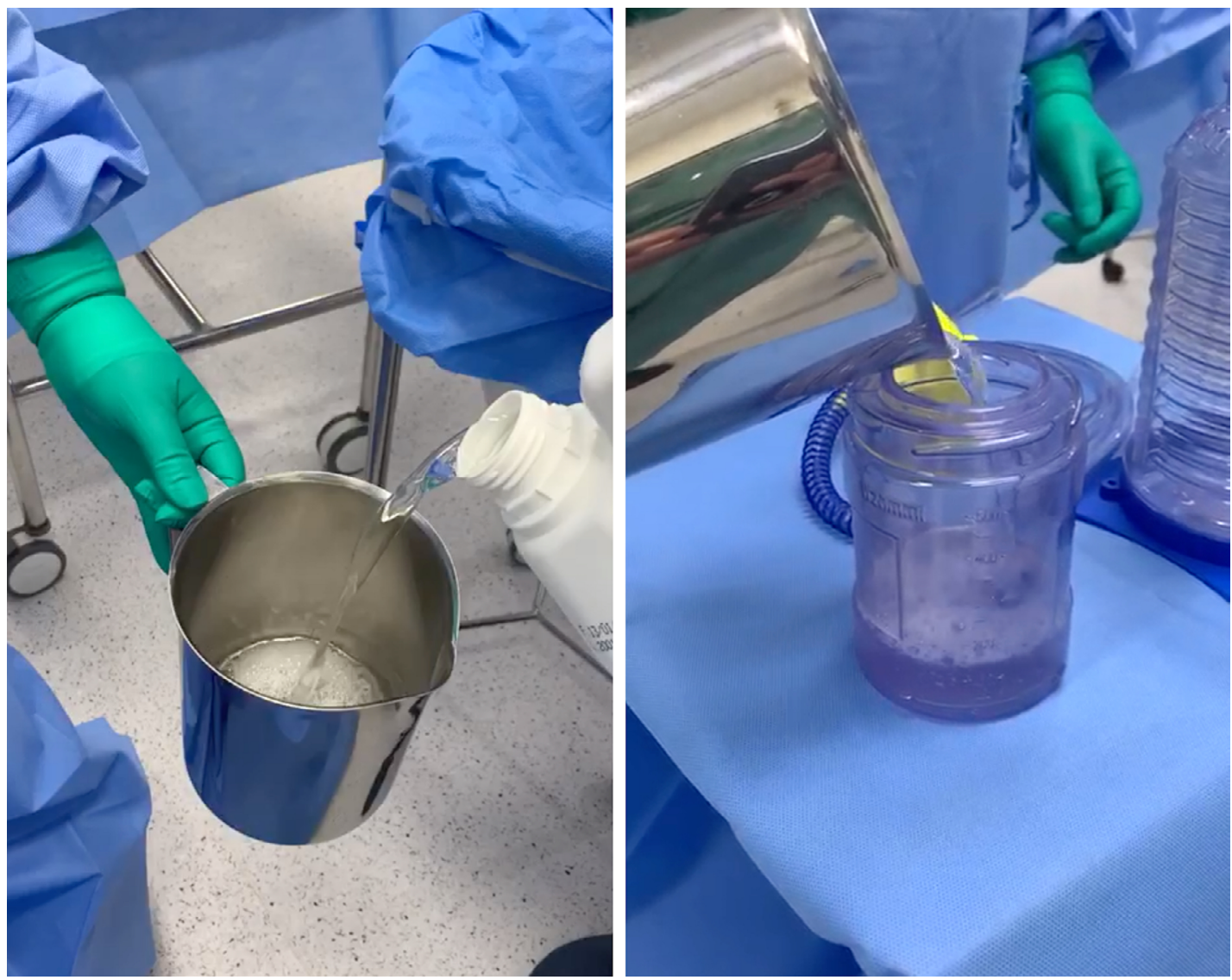

Figura 1. Demonstração da colocação da solução no recipiente de selo d'água.
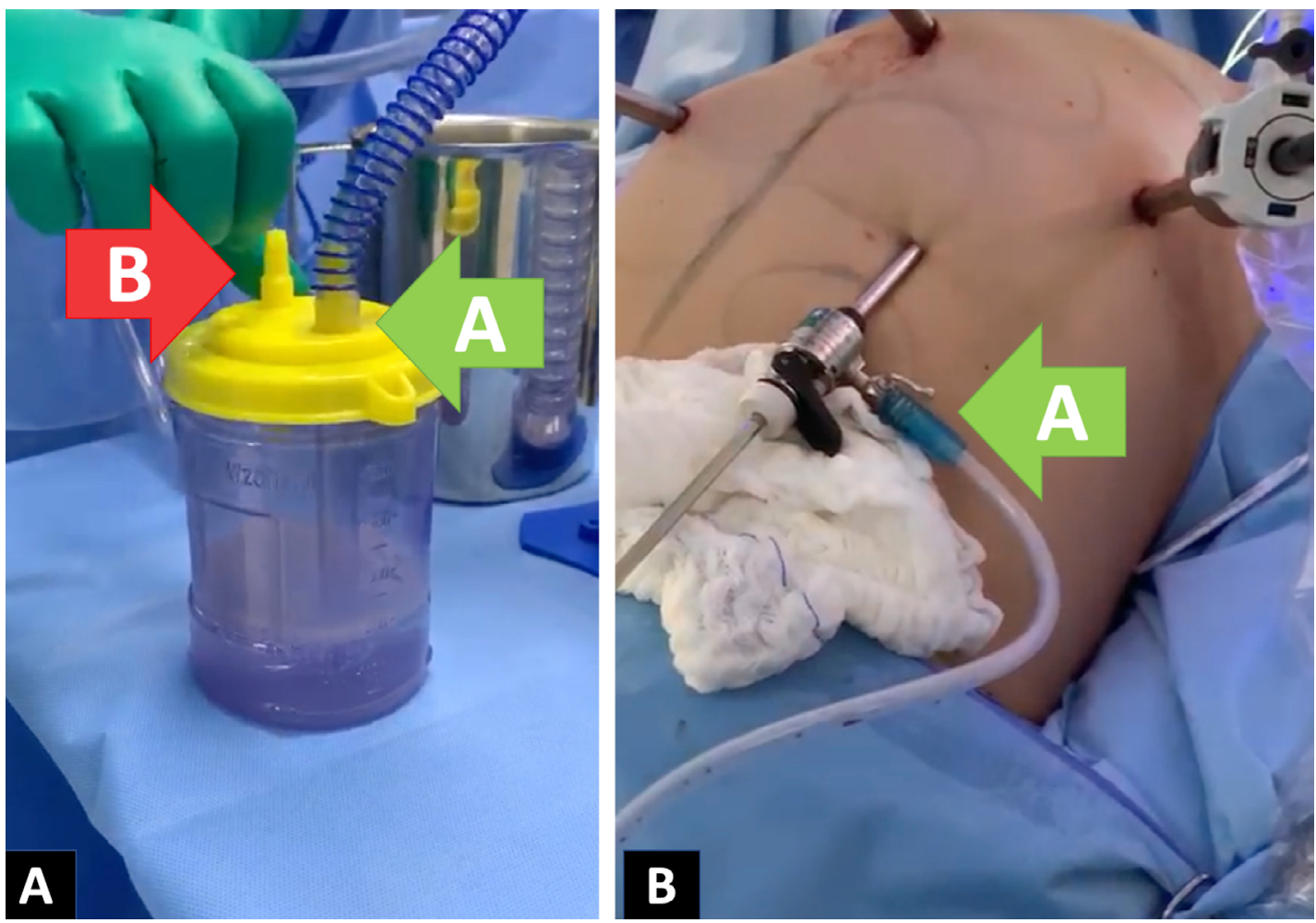

Figura 2. 2A: Dispositivo de selo d'água com orifícios A e B para conexão dos cabos de aspiração. 2B: Conexão da outra extremidade do cabo de aspiração no trocater cirúrgico. 
Antes da introdução de qualquer trocater, sempre certificar-se de que a válvula do mesmo esteja fechada para evitar escape inadvertido do ar do pneumoperitônio para o ambiente. Quanto ao tamanho de incisões, sempre o menor possível para também evitar escape.

Sistema de adaptação: Uma vez introduzidos os trocaters, deve-se conectar a outra ponta do cabo proveniente da conexão $\mathrm{A}$ a um dos trocaters que não seja o que contenha o insuflador (Figura 2B). Em seguida, deve-se utilizar o segundo cabo e conectar uma das pontas ao orifício B da tampa do selo d'água e a outra extremidade a um dispositivo de aspiração contínua da sala em baixo fluxo (Figura 3). Após correta vedação e funcionamento do dispositivo em aspiração a vácuo, procede-se com a abertura da válvula do trocater.

Uma outra maneira de também realizar um circuito de aspiração fechado na ausência das substâncias químicas previamente citadas é através da conexão de um filtro de ventilação mecânica e seu adaptador de tubo orotraqueal conectado na porção terminal do cabo de aspiração saindo do trocater cirúrgico. A parte remanescente do filtro é então conectada a um segundo cabo plástico, direcionando o resíduo ao dispositivo de selo d'água preenchido por soro fisiológico.

\section{Bisturis elétricos ou pinças ultrassônicas:}

Utilizar o mínimo possível, na menor potência de coagulação possível, para evitar dispersão das partículas de aerossol.

Desinsuflação: Ao término da cirurgia, a injeção de dióxido de carbono é cessada e devese aspirar o máximo possível do ar intracavitário antes da remoção de qualquer trocater. Uma vez terminada a aspiração e o abdome esteja plano, é feita a colocação do braço do cirurgião internamente ao saco plástico transparente esterilizado recobrindo parcialmente o braço e a totalidade da mão.

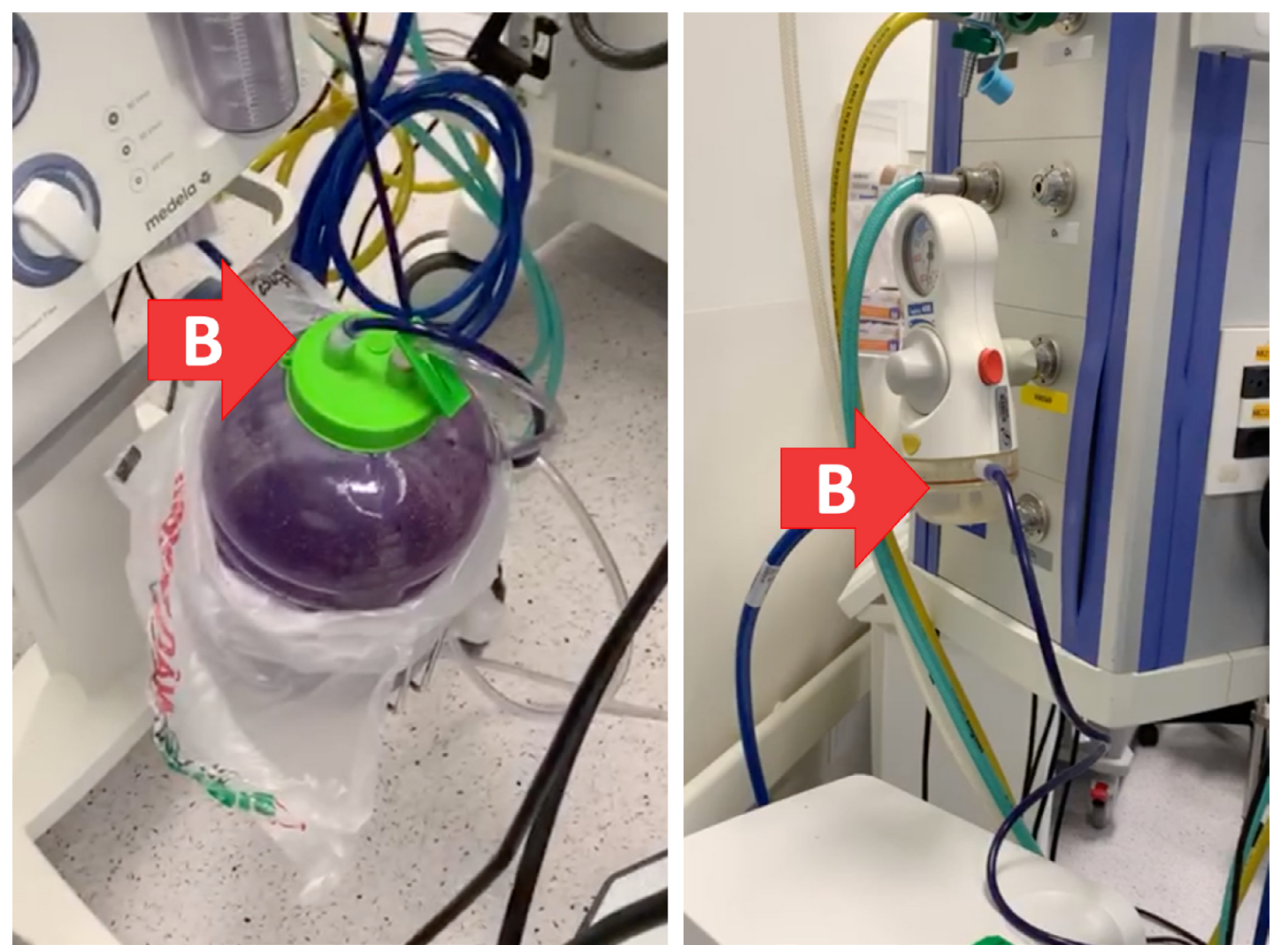

Figura 3. Dispositivo de aspiração contínua ligado a extremidade final do cabo plástico no orifício B. 
A mão recoberta efetua a remoção dos trocaters dessa maneira "encapada" enquanto a outra mão pressiona o plástico para vedação completa do sítio da incisão, protegendo a equipe contra possível spray de secreções e aerossol, assim como de disseminação para o ambiente. Os materiais descartáveis utilizados devem ser colocados em sacos plásticos de descarte habituais, fechando-o e torcendo o pescoço da bolsa com a confecção de um nó, garantindo a vedação com o ambiente.

\section{DISCUSSÃO}

A pandemia da COVID-19 é assunto de suma importância e um dos mais veiculados assuntos na atualidade, seja em revistas científicas, mídias convencionais ou sociais. Acredita-se que a cooperação e a troca de informações em âmbito global objetivando melhores cuidados tanto de pacientes como de profissionais de saúde nunca foi tão relevante como nos tempos atuais.

A demanda colossal por atendimentos médicos e a saturação do sistema de saúde em âmbito mundial expôs a sociedade a grande escassez de suprimentos e materiais necessários para os cuidados de pacientes. Em meio à pandemia, no entanto, os procedimentos cirúrgicos ainda ocupam razoável parcela da atividade hospitalar mesmo após enorme mobilização do setor com suspensões e adiamentos de casos não essenciais. Casos de emergência, urgências e o grupo de enfermos com doenças oncológicas, contudo, não têm como esperar o completo controle viral. Shaoqing et al. ${ }^{12}$, recentemente descreveram um grupo de 34 pacientes com necessidade de internação hospitalar por manifestação da COVID-19, após terem sido submetidos a procedimentos cirúrgicos. No estudo, pacientes sem sintomas ou sinais para infecção viral residindo na cidade de Wuhan foram submetidos a cirurgias, com a totalidade deles evoluindo com pneumonia, no pós-operatório. Dados como esses implicam na possibilidade da operação ter acelerado e até agravado a progressão da doença.
É de conhecimento global que profissionais médicos que cuidam de pacientes com COVID-19 têm alto risco de contrair a infecção ${ }^{13}$. Procedimentos passíveis de disseminar aerossóis, como ventilação não invasiva (VNI), cânula nasal de alto fluxo, bolsaventilação por máscara e intubação são os de maior risco ${ }^{14}$. Lima et al. ${ }^{15}$ recém publicaram sobre a adaptação e a educação de médicos emergencistas e cirurgiões para realizarem procedimentos de cricotireoidostomia e traqueostomia, oferecendo alternativas no manejo cirúrgico da via aérea nestes pacientes. Nesta mesma linha, procedimentos de cirurgia minimamente invasivas que dispõem de fluxo de dióxido de carbono e aumento da pressão intra-abdominal também promovem dispersão de aerossóis. Richard et al. ${ }^{16}$ demonstraram a contaminação ambiental consistente por sangue e líquidos corporais durante a evacuação rápida do pneumoperitônio.

Casos recentes evidenciam que não apenas os pacientes subclínicos podem transmitir o vírus de maneira eficaz, como também podem liberar grandes quantidades do vírus e transmiti-los a outros, mesmo após a recuperação da doença aguda ${ }^{17}$. Esses achados justificam medidas agressivas dirigidas ao uso de equipamentos de proteção individual para garantir a segurança dos profissionais de saúde durante esse surto. Todo profissional da área de saúde envolvido no tratamento de pacientes durante a pandemia de COVID-19 deve seguir as precauções de higiene das mãos e a colocação de equipamentos de proteção individual.

A eficácia questionável e possíveis limitações do método relatado para diminuição da dispersão de aerossol no paciente cirúrgico são notórios. Estudos com adequado nível de evidência sobre a efetividade não existem. Acreditamos que nos tempos vigentes de pandemia e incertezas, a verdadeira disseminação que interessa é a de informação, ainda que preliminar, porém com intuito de propagar melhores cuidados aos que precisam. 


\section{CONCLUSÃO}

A sistematização de cuidados no ato cirúrgico pode significar mais um auxílio na prevenção da transmissão viral. A dispersão de aerossol em sala cirúrgica pode ser evitada por meio de medidas simples e sem necessidade de dispositivos de alto custo ou por vezes indisponíveis.

\title{
A B S T R A C T
}

\begin{abstract}
The coronavirus infection, also known as SARS-COV2, has proven to be potentially fatal, representing a major global health problem. Its spread after its origin in the city of Wuhan, China has resulted in a pandemic with the collapse of the health system in several countries, some with enormous social impact and expressive number of deaths as seen in Italy and Spain. Extreme intra and extra-hospital measures have been implemented to decrease the transmission and dissemination of the COVID-19. Regarding the surgical practice, a huge number of procedures considered non-essential or elective were cancelled and postponed until the pandemic is resolved. However, urgent and oncological procedures have been carried out. In this publication, we highlight and teach adaptations to be made with commonly used materials in laparoscopy to help prevent the spread and contamination of the healthcare team assisting surgical patients.
\end{abstract}

Keywords: Laparoscopy. Aerosol Propellants. Coronavirus. Pandemics. Perioperative Period.

\section{REFERÊNCIAS}

1. Du Toit A. Outbreak of a novel coronovirus. Nat Rev Microbiol. 2020;18(3):123.

2. Chen H, Guo J, Wang C, Luo F, Yu X, Zhang W, et al. Clinical characteristics and intrauterine vertical transmission potential of COVID-19 infection in nine pregnant women: a retrospective review of medical records. Lancet. 2020;395(10226):809-15.

3. Correia MITD, Ramos RF, Bahten LCV. The surgeons and the COVID-19 pandemic. Rev Col Bras Cir. 2020;47:e20202536.

4. COVID-19: Nota do CBC/SBCO/SBOT sobre suspensão de cirurgias eletivas. 2020 Mar 28.

5. Alp E, Bijl D, Bleichrodt RP, Hansson B, Voss A. Surgical smoke and infection control. J Hosp Infect. 2006;62(1):1-5.

6. Choi SH, Kwon TG, Chung SK, Kim TH. Surgical smoke may be a biohazard to surgeons performing laparoscopic surgery. Surg Endosc. 2014;28(8):2374-80.

7. Zheng $\mathrm{MH}$, Boni L, Fingerhut $\mathrm{A}$. Minimally invasive surgery and the novel coronavirus outbreak: lessons learned in China and Italy. Ann Surg. 2020 Mar 26. doi: 10.1097/SLA.0000000000003924.

8. Dexter F, Parra MC, Brown JR, Loftus RW. Perioperative COVID-19 defense: an evidence-based approach for optimization of infection control and operating room management. Anesth Analg. 2020 Mar 26. doi: 10.1213/ANE.0000000000004829.
9. Cheung JC, Ho LT, Cheng JV, Cham EYK, Lam KN. Staff safety during emergency airway management for COVID-19 in Hong Kong. Lancet Respir Med.2020;9(4)e19.

10. World Health Organization (WHO). Water, sanitation, hygiene, and waste management for the COVID-19 virus: interim guidance. [Internet]. 2020. [citado 2020 mar 06]. Disponível em: https://www.who.int/ publications-detail/water-sanitationhygiene-andwaste-management-for-covid-19

11. Wang XW, Li JS, Jin $M$, Zhen $B$, Kong QX, Song $N$, et al. Study on the resistance of severe acute respiratory-associated coronavirus. J Virol Methods. 2005;126(1-2):171-7.

12. Lei $S$, Jiang F, Su W, Chen $C$, Chen J, Mei W, et al. Clinical characteristics and outcomes of patients undergoing surgeries during the incubation period of COVID-19 infection. EClinicalMedicine. 2020; https://doi.org/10.1016/j.eclinm.2020.100331.

13. Chang, Xu H, Rebaza A, Sharma L, Dela Cruz CS. Protecting health-care workers from subclinical coronavirus infection. Lancet Respir Med. 2020;8(3):e13.

14. Tran K, Cimon K, Severn M, Pessoa-Silva CL, Conly J. Aerosol generating procedures and risk of transmission of acute respiratory infections to healthcare workers: a systematic review. PLoS One. 2012;7(4):e35797.

15. Lima DS, Ribeiro Junior MF, Vieira-Jr HM, T Campos, Di Saverio S. Alternativas para o estabelecimento de via aérea cirúrgica durante a pandemia de COVID-19. Rev Col Bras Cir. 2020;47(1):e20202549. 
16. Englehardt RK, Nowak BM, Seger MV, Duperier FD. Contamination resulting from aerosolized fluid during laparoscopic surgery. JSLS. 2014;18(3):e2014.00361.

17. Rothe $C$, Schunk M, Sothmann P, Bretzel G,Froeschl G, Wallrauch C, et al. Transmission of 2019$\mathrm{nCoV}$ infection from an asymptomatic contact in Germany. N Engl J Med. 2020;382(10):970-1.

Recebido em: 06/04/2020

Aceito para publicação em: 06/04/2020
Conflito de interesses: Não

Fonte de financiamento: Não

\section{Endereço para correspondência:}

Andre Luiz Gioia Morrell

E-mail: andremorrell@gmail.com

alternativo: andrelgmorrell@gmail.com

(c) (i) 